\title{
Analysis of Potentials of Wave Power Plant for Fisherman Boats in Selayar Islands
}

\author{
Asrianto $^{\mathrm{a}}$, Luther Sule ${ }^{\mathrm{b}}$, Nasaruddin Asis $^{\mathrm{c}}$ \\ aDepartment of Mechanical Engineering, Hasanuddin University. Email:anto199491@gmail.com \\ bepartment of Mechanical Engineering, Hasanuddin University. Email:luther.sule@ yahoo.co.id \\ cDepartment of Mechanical Engineering, Hasanuddin University. Email:nasruddinazis@ unhas.ac.id
}

\begin{abstract}
This research aims to determine the design of ocean wave power generation equipment for fishing boats in Selayar Islands and to determine how much power is generated by ocean wave power generation equipment. The results showed that the power generated with an arm length of 2 meters with a wave height of $0.1-0.6$ meters adjusted to the up and down of the arms produced $71.7 \mathrm{~W}, 83.72 \mathrm{~W}$, 168.28 W, 240.4 W, 277.64 W and 483.2 W. Whereas an arm length of 4 meters with a wave height can reach 0.1 - 1 meter producing power of $35.76 \mathrm{~W}, 59.75 \mathrm{~W}, 72.24 \mathrm{~W}, 84.35 \mathrm{~W}, 144.51 \mathrm{~W}, 471.51 \mathrm{~W}, 596.64 \mathrm{~W}, 606 \mathrm{~W}, 642.83 \mathrm{~W}$, and $800.58 \mathrm{~W}$.
\end{abstract}

Keywords: Electric alternators; fishing boats, ocean waves

\section{Introduction}

Indonesia as an archipelago country with an area of $1,904,556 \mathrm{~km}^{2}$ consisting of; 17,508 islands, 5.8 million $\mathrm{km}^{2}$ of ocean and 81,290 million $\mathrm{km}$ of beach length, the potential of ocean energy, especially ocean waves, is very potential to be empowered as a new and renewable alternative primary energy especially for power generation. With a long coastline, wave energy potential is very significant and if used properly [1], it can be a very large source of energy. The practical potential of Indonesian wave energy is estimated at around 17,989 MW [2].

Astronomically, the Selayar islands are located between $5^{\circ} 42^{\prime}-7^{\circ} 35^{\prime}$ south latitude and $120^{\circ} 15^{\prime}-122^{\circ}$ $30^{\prime}$ east longitude. Based on its geographical position, the Selayar islands have boundaries: North - Bulukumba Regency, East - Flores Sea, West - Flores Sea and Makassar Strait, South - East Nusa Tenggara Province. Selayar Islands has an area of $10,503.69 \mathrm{~km}^{2}$ with $1,357.03 \mathrm{~km}^{2}$ of land area and sea area of $9,146.66 \mathrm{~km}^{2}$ [3].

Fishermen in Selayar Islands Regency use lifter nets powered by an average of 3-4 engines: 3 main engines push the boat and 1 engine to turn on lights that attract fish. This second engine is usually powered by diesel. Consistent diesel consumption can cause an energy crisis. The energy crisis occurred as a result of increasing scarcity of crude oil and increasing energy demand. A

${ }^{*}$ Corresponding author. Tel.: +62 823-9658-0889

Jalan Poros Malino km. 6 Bontomarannu, Gowa

South Sulawesi, Indonesia 92171 breakthrough in alternative and renewable energy sources is increasingly needed [4]. An alternative energy source that might be a solution to this looming crisis is the ocean waves that have long been known as enormous energy sources [5], [6].

Several ocean wave power generation systems have been developed by various researchers in the world, including ocean wave power station oscillating system, water wave power plant with buoy system, ocean wave power plant with crank system, etc.

From several published studies discussing the topic of power plants using ocean wave energy in many regions throughout the world, inspired the authors to design an oscillation of wave energy power plants that can be installed on fishing boats in the fishing village of Selayar islands regency.

\section{Literature Review}

\subsection{Ocean waves}

Sea wave is the movement of the rise and fall of water in the direction perpendicular to the surface of the seawater that forms a curve or graph sinusoidal. The wind that moves its power to the surface of the water, causing ripples, the strains/hills and turns into sea waves or waves [7]. Ocean waves have potential and kinetic energy that can be calculated with the equation from Kim Neilsen. By using this equation we can get some energy contained in high tidal waves [8]. 
The equation for ocean wave potential energy is:

$$
E_{w}=\frac{1}{4} \cdot \rho \cdot g \cdot a^{2} \cdot \lambda
$$

The power that can be generated from the energy of sea waves in coastal waters in Indonesia can be obtained by using the following equation:

$$
P_{w}=\frac{\frac{1}{4} \cdot \rho \cdot g \cdot a^{2} \cdot \lambda}{T}
$$

where

$$
\begin{array}{ll}
P_{w} & =\text { Sea Wave Power } \\
\rho & =\text { Seawater Density } \\
\alpha & =\text { Amplitude of Ocean Waves } H / 2 \\
g & =\text { Acceleration of Gravity } \\
\lambda & =\text { Wavelength } \\
T & =\text { Wave Period }
\end{array}
$$

Sea waves are sea water propagations that fluctuate up and down due to being generated mainly by winds in deep sea generation areas. In general, the shape of ocean waves in nature is very complex and difficult to describe systematically because it is not linear, three-dimensional, and has a different height and wave period. Ocean waves are generated by wind (wind waves), the force of the sun and moon (tides), volcanic eruptions or earthquakes in the sea (tsunami) [9].

The shape and propagation of waves that vary and are irregular greatly affect the characteristics of the waves that occur in these waters. In addition to changes in height, length and speed of waves also occur other phenomena such as silting, refraction, diffraction and reflection before the wave breaks. Wave siltation is the process of decreasing the wave height due to changes in depth where the wave velocity decreases and consequently there is also a refraction because the direction of motion of the wave peaks follows the contour shape of the ocean depth. Refraction is emphasized on the change in wave height due to the bending of the wave peak direction. While diffraction is the process of moving towards a protected area, causing waves [10].

The wave arrival period can be calculated using the equation suggested by Nielsen [11] in Utami [12] as follows:

$$
T=3.55 \times \sqrt{H}
$$

where

$$
\begin{array}{ll}
T & =\text { period of wave }(\mathrm{s}) \\
H & =\text { wave height }(\mathrm{m})
\end{array}
$$

By knowing the estimated period of the wave arrival, then we can calculate the wave length and velocity with the equation according to Ross [13] in Utami [12] as follows:

$$
\lambda=5.12 \times T^{2}
$$

where :

$$
\begin{array}{ll}
\lambda & =\text { wavelength }(\mathrm{m}) \\
T & =\text { period of wave }(\mathrm{s})
\end{array}
$$

\subsection{Alternator}

The application of the concept of electromagnetic induction is used in dynamos or generators. This tool converts mechanical or kinetic energy into electrical energy. The working principle of a dynamo or generator is of two kinds, including:

- The coil rotates in a magnetic field.

- The magnet rotates between several coils.

When the coil is rotated between the magnetic poles so that it cuts the magnetic field lines, the coil will receive a magnetic flux of varying magnitude. Changes in magnetic flux can cause induction emf. Kinetic energy on the dynamo or generator can be obtained from the rotation of the wheels, wind, and waterfalls. In general, based on the current generated, the dynamo or generator can be divided into two types, namely AC (alternating current) and DC (direct current). In a dynamo, there is a rotating part called a rotor, while the stationary part is called a stator [14].

\section{Research Methodology}

\subsection{Time and place of research}

This research was conducted from January to December 2019 in the waters of the western Selayar Islands, Selayar Islands Regency. About the Analysis of Wave Power Generation for fishing boats in the Selayar Islands. The design tools used in the study are as follows:

Figure 1 shows the oscillating wave energy power plant design on a fishing boat. The design consists of parts such as:
a. Alternator
b. Freewheel
c. Chain
d. V-belt
e. Pully
f. buoy mechanism
g. Bearing
h. Spring

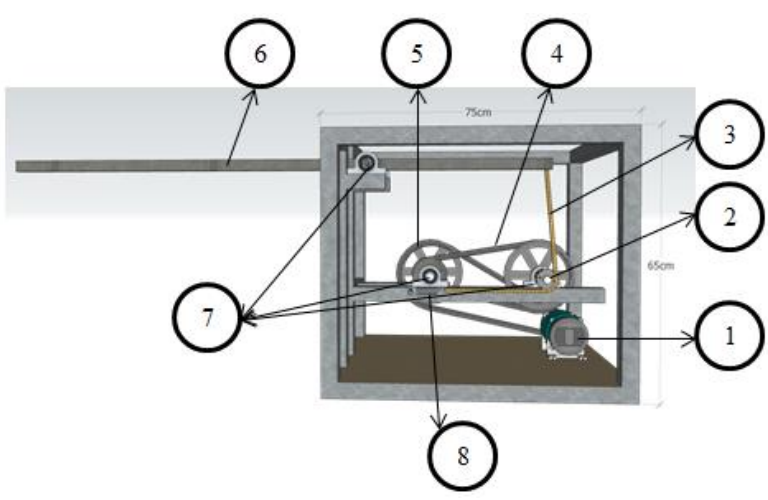

Figure 1. Sea wave power plant 


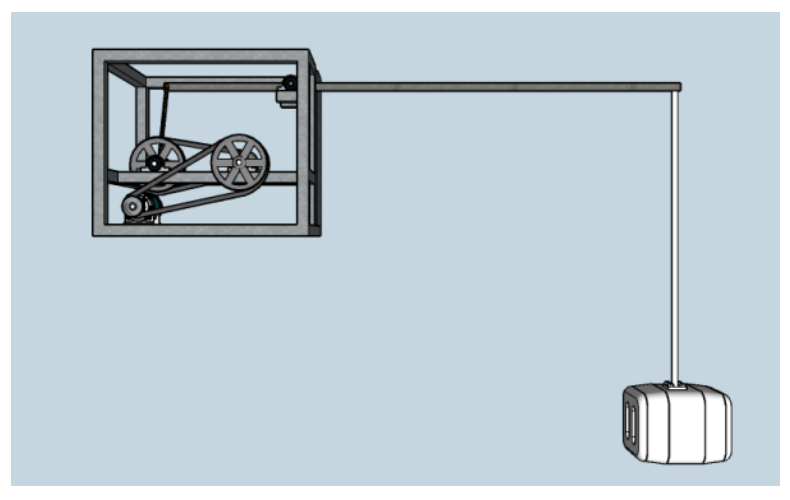

Figure 2. Side view of the equipment

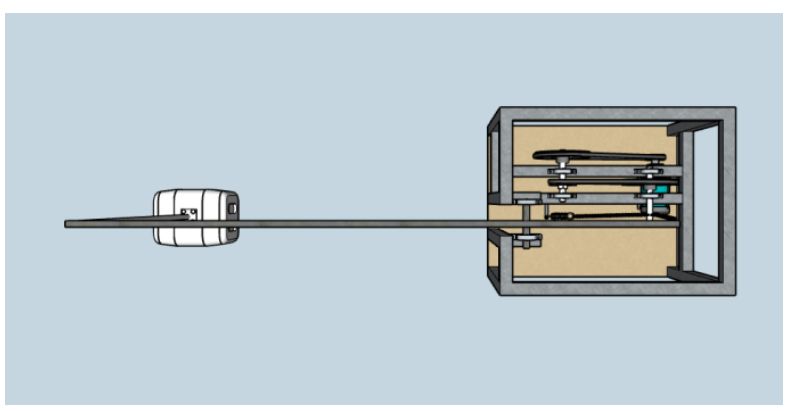

Figure 3. Top view of the equipment

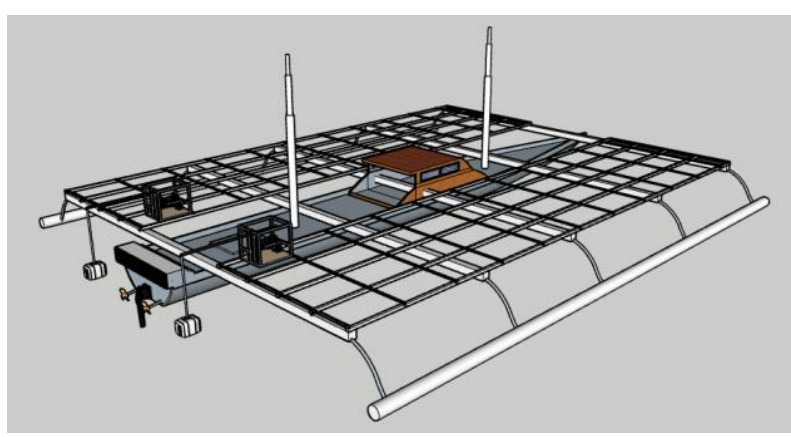

Figure 4. Equipment position on the boat

Technical calculations are needed to get the value of sea wave power which is a comparison to get the value of efficiency from ocean wave power plant. The amount of power produced by each is calculated as:

$$
\begin{aligned}
& T=3.55 \times \sqrt{H} \\
& \lambda=5.12 \times T^{2} \\
& P_{w}=\frac{\frac{1}{4} \cdot \rho \cdot g \cdot a^{2} \cdot \lambda}{T} \\
& \eta=\frac{P_{\alpha}}{P_{w}} \times 100 \%
\end{aligned}
$$

\subsection{Testing method}

- The alternator is connected to the battery according to the set sequence so that the alternator can charge.

- Put the charging indicator light on the battery

- Move the arm on the sea wave power plant in accordance with the frequency of the ocean waves.
- Measure the rpm of the alternator pully using a tachometer and the power coming out of the alternator with a digital multimeter.

- Take note of the rpm and voltage generated after moving the arm of a sea wave power plant.

\subsection{Data analysis}

The data analysis technique used in this study is a quantitative data analysis technique with descriptive statistics using equations. The data obtained are tabulated in tabular form and interpreted in graphical form which will then become a reference in making a description.

\section{Results and Discussion}

Sea wave data used are sea waves in the waters of the western islands of Selayar islands. The data can be seen in Table 1. Figure 5 is the tool used for testing in research data collection.

\subsection{Example calculations}

Taken from significant maximum mean sea wave height data.

a. Density of seawater $=1030 \mathrm{~kg} / \mathrm{m}^{3}$

b. Maximum average wave height $=1$ meter

c. Acceleration of gravity $=9.8 \mathrm{~kg} \cdot \mathrm{m} / \mathrm{s}$

d. Wave period $=T=3.55 \times \sqrt{H}$ where $\mathrm{H}$ is the wave height.

e. Period for maximum wave height;

- $T=3.55 \times \sqrt{1}$

- $T=3.55 \mathrm{~s}$

Table 1. Sea wave height in the waters of the western islands of Selayar Island

\begin{tabular}{lcc}
\hline \multicolumn{1}{c}{ Month } & $\begin{array}{c}\text { Average Sea Wave } \\
\text { Height }(\mathrm{m})\end{array}$ & $\begin{array}{c}\text { Maximum Wave } \\
\text { Height }(\mathrm{m})\end{array}$ \\
\hline January & $0.75-1.0$ & $1.0-2.0$ \\
February & $0.75-1.0$ & $1.0-2.0$ \\
March & $0.5-.075$ & $1.0-1.25$ \\
April & $0.1-0.5$ & $0.5-0.75$ \\
June & $0.5-0.75$ & $0.75-1.0$ \\
July & $0.5-0.75$ & $0.75-1.0$ \\
August & $0.5-0.75$ & $1.0-1.25$ \\
September & $0.5-0.75$ & $1.0-1.25$ \\
October & $0.5-0.75$ & $1.0-1.25$ \\
November & $0.1-0.5$ & $0.75-1.0$ \\
December & $0.1-0.5$ & $0.75-1.0$ \\
\hline
\end{tabular}

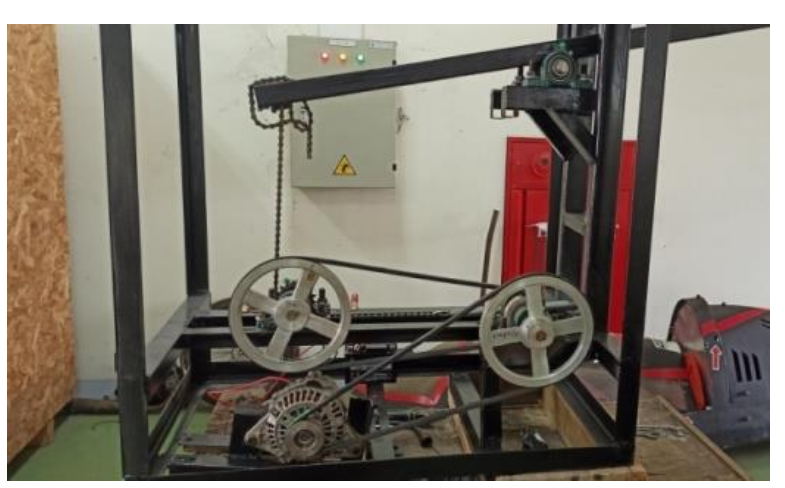

Figure 5. Sea wave power generation equipment 
f. Wavelength $=\lambda=5.12 \times T^{2}$ then

g. Wavelength for maximum wave height

- $\lambda=5.12 \times 3.55^{2}$

- $\lambda=64.5$ meter

h. Sea wave amplitude $=\frac{H}{2}=0.5$ meters $\frac{1}{2}$

Solution:

The equation for ocean wave potential energy is:

$$
E_{w}=\frac{1}{4} \cdot \rho \cdot g \cdot a^{2} \cdot \lambda
$$

Power that can be generated from the energy of sea waves in coastal waters in Indonesia can be obtained by using the equation:

$$
P_{w}=\frac{\frac{1}{4} \cdot \rho \cdot g \cdot a^{2} \cdot \lambda}{T}
$$

Then,

$$
\begin{aligned}
P_{w} & =\frac{\frac{1}{4} \cdot 1030 \frac{\mathrm{kg}}{\mathrm{m}^{3}} \cdot 9.8 \frac{\mathrm{m}}{\mathrm{s}^{2}} \cdot 0.5^{2} \mathrm{~m} \cdot 64.5 \mathrm{~m}}{3.55 \mathrm{~s}} \\
& =45849.5 \mathrm{watt}
\end{aligned}
$$

The power generated from the tool for a 1 meter wave height with an arm length of 4 meters is 800.58 watts, so the efficiency is

$$
\eta=\frac{P_{\alpha}}{P_{w}} \times 100 \%
$$

Then, the efficiency is

$$
\begin{aligned}
\eta & =\frac{800.58}{45849.5} \times 100 \% \\
& =1.746 \%
\end{aligned}
$$

\subsection{Variation in arm length of 2 meters}

Figure 6 shows the number of rotations (n) the tool can produce, with wave height (S1) and variations in arm length of 2 meters. At a wave height of $0.1-0.6 \mathrm{~m}$, it can produce $301.5 \mathrm{rpm}, 395.5 \mathrm{rpm}, 487.6 \mathrm{rpm}, 540 \mathrm{rpm}, 675$ $\mathrm{rpm}$, and $758.5 \mathrm{rpm}$. The mass of the buoy used at 2 meters arm length is $5 \mathrm{~kg}$. Thus, it can be concluded that the higher the wave, the more rotation that can be produced by the instrument. In addition, it can also be influenced by the length of the arm.

Figure 7 shows the amount of power produced (P), with wave height and arm length variation of 2 meters. At a minimum wave height of $0.1-0.6 \mathrm{~m}$, each produces 71.7 $\mathrm{W}, 83.72 \mathrm{~W}, 168.28 \mathrm{~W}, 240.4 \mathrm{~W}, 277.64 \mathrm{~W}$ and $483.2 \mathrm{~W}$ waves respectively. can affect the amount of power. In addition, the number of turns on the alternator pully also greatly affects the amount of power that can be generated. From the following graph we can see an increase in power generated based on rpm.

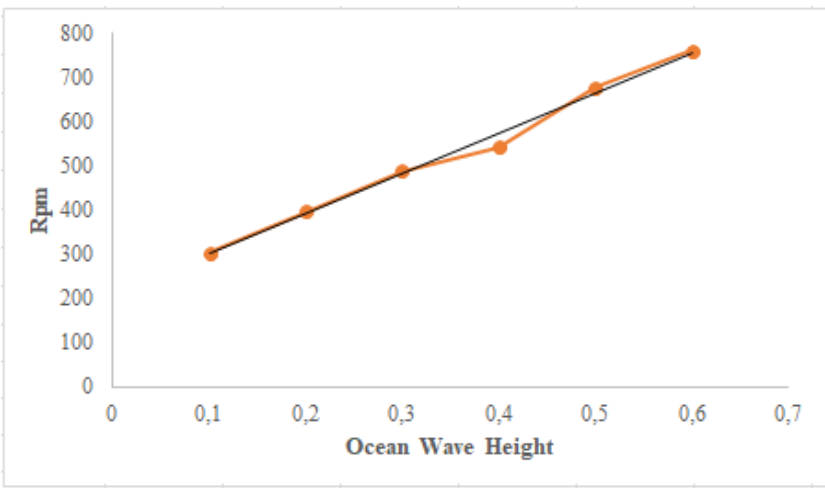

Figure 6. Wave height $(\mathrm{m})$ and alternator pulley rotation (rpm) arm length of 2 meters

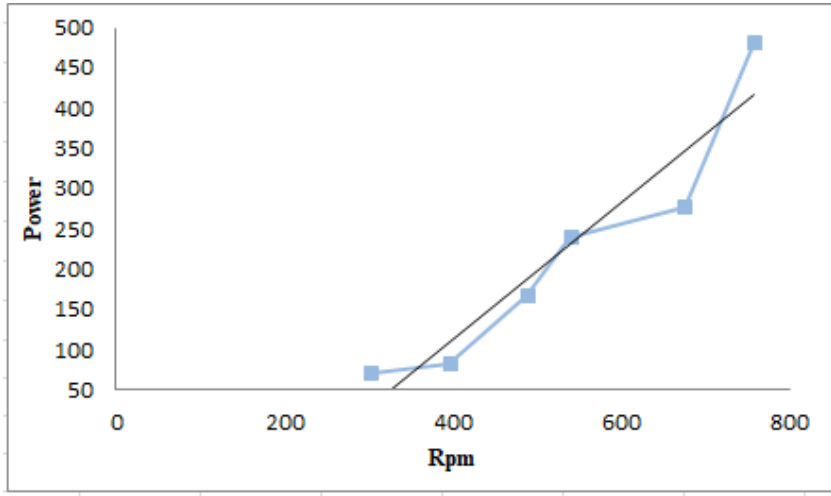

Figure 7. Rpm and power generated $(\mathrm{P})$

\subsection{Variation in arm length of 2 meters}

Figure 8 shows the number of rounds (n) that a sea wave power plant can produce, with wave height and variations in arm length of 4 meters. At a wave height of 0.1-1 m, it can produce $194.4 \mathrm{rpm}, 329.4 \mathrm{rpm}, 356.2 \mathrm{rpm}$, $375.3 \mathrm{rpm}, 447 \mathrm{rpm}, 688.2 \mathrm{rpm}, 710 \mathrm{rpm}, 1023.2 \mathrm{rpm}$, $1105 \mathrm{rpm}$, and $1194.2 \mathrm{rpm}$. It can be concluded that the higher the wave, the more rotation the instrument can produce. The resulting $\mathrm{Rpm}$ is different from the arm length of 2 meters when it is tested. The buoy mass used at the arm length of 4 meters is $3 \mathrm{~kg}$. this shows that arm length also affects the buoy mass.

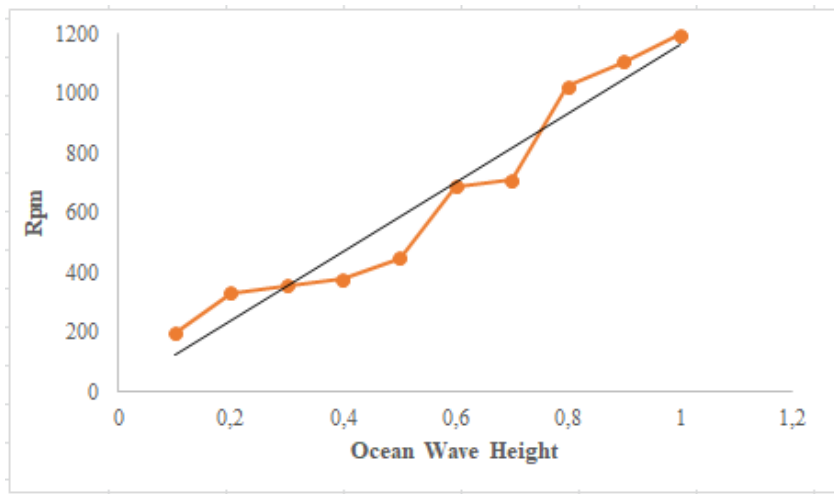

Figure 8 . Wave height $(\mathrm{m})$ and alternating pully alternator (rpm) arm length 4 meters 


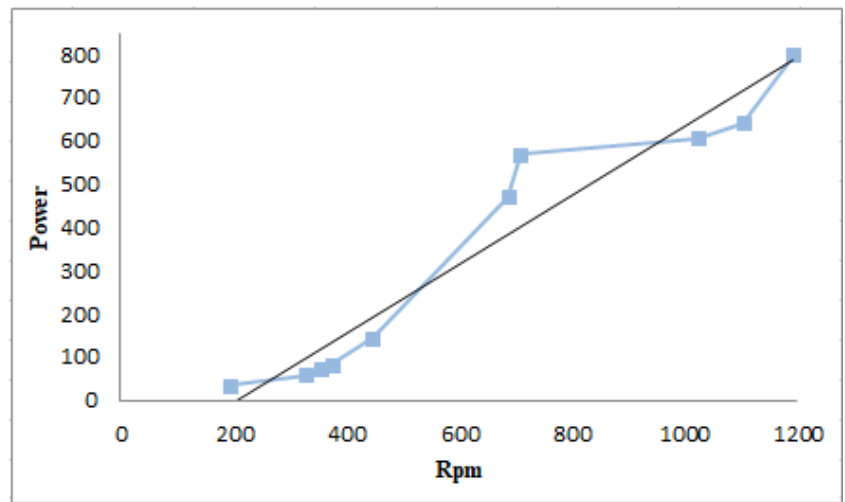

Figure 9. Rpm and power generated (P)

Figure 9 shows that the power generated $(\mathrm{P})$ with wave height and arm length variation is 4 meters. At a minimum wave height of $0.1-1 \mathrm{~m}$, it produces $35.76 \mathrm{~W}, 59.75 \mathrm{~W}$, $72.24 \mathrm{~W}, 84.35 \mathrm{~W}, 144.51 \mathrm{~W}, 471.51 \mathrm{~W}, 596.64 \mathrm{~W}, 606$ $\mathrm{W}, 642.83 \mathrm{~W}$ and $800.58 \mathrm{~W}$. Wave height can affect the magnitude of the power. In addition, the length of the arm also affects the power generated by the tool. the number of turns on the alternator pully also greatly influences the amount of power that can be generated. From the following graph we can see an increase in power.

\section{Conclusion}

The results showed that, the power generated with an arm length of 2 meters with a wave height of $0.1-0.6$ meters adjusted to the ups and downs of the arms produced $71.7 \mathrm{~W}, 83.72 \mathrm{~W}, 168.28$ respectively W, $240.4 \mathrm{~W}, 277.64$ $\mathrm{W}$ and $483.2 \mathrm{~W}$. Whereas an arm length of 4 meters with a wave height can reach 0.1 - 1 meter producing power of $35.76 \mathrm{~W}, 59.75 \mathrm{~W}, 72.24 \mathrm{~W}, 84.35 \mathrm{~W}, 144.51 \mathrm{~W}, 471.51$ $\mathrm{W}, 596.64 \mathrm{~W}, 606 \mathrm{~W}, 642.83 \mathrm{~W}$ and $800.58 \mathrm{~W}$.

\section{References}

[1] A. Zamri, Yusri, Asmed, E. Adril, and J. W. Soedarsono, Four Pendulum Systems Ocean Wave Power Plant. Padang State Polytechnic, 2014.

[2] D. Anggraini, M. I. Al Hafiz, A. F. Derian, and Y. Alfi, "Quantitative Analysis of Indonesia Ocean Wave Energy Potential Using Oscillating Water Column Energy Converter," Int. J. Sci. Technol., vol. 1, no. 1, pp. 228-239, 2015.

[3] Selayar Regency Statistics Agency, Selayar Islands Regency in Figures 2017. Selayar, 2017.

[4] D. N. Sugianto, Kunarso, M. Helmi, and I. Alifdini, "Wave Energy Reviews in Indonesia," Int. J. Mech. Eng. Technol., vol. 8, no. 10, pp. 448-459, 2017.

[5] M. A. Marfai, D. W. Tyas, I. Nugraha, A. Fitriatul'Ulya, and W. Riasasi, "The Morphodynamics of Wulan Delta and Its Impacts on the Coastal Community in Subdistrict Buildings, Demak Regency, Indonesia," J. Environ. Prot. (Irvine,. Calif)., vol. 7, pp. 60-71, 2016.

[6] F. D. Wijaya, Sarjiya, and M. R. P. Sugita, "Optimizing Tri-Core Permanent-Magnet-Linear-Generator DirectDrive Wave-EnergyConversion System Design for Sea Wave Characteristics in South Coast Yogyakarta," Int. J. Electr. Comput. Eng., vol. 7, no. 2, pp. 610-618, 2017.

[7] A. Mandiharta, Study of Potential Development of Tidal Energy as Alternative Energy. Elelctrical Engineering Study Program, Engineering Faculty, Udayana University, 2007.

[8] B. Murdani, Design Analysis of Sea Wave Power Plant with Oscillating Water Column System at Baron Beach. Jakarta, 2008.

[9] M. M. Danial, Coastal Engineering. Bandung: Alfabeta, 2008.

[10] W. A. Pratikto et al., Coastal Protection Structures. Surabaya: Marine Engineering, Sepuluh November Technology Institute, 2000.

[11] K. Nielsen, "On the Performance of Wave Power Converter," in Int. Sym. Util.of Ocean Waves, 1986.

[12] S. R. Utami, Study of the Potential Sea Wave Power Generation Using the Oscillating Water Column (OWC) System in Thirty Indonesian Water Areas. Electrical Engineering Department, Engineering Faculty, Indonesia University, 2010.

[13] D. Ross, Energy from the Waves, 2nd ed. Perganon Press, 1980.

[14] B. Lu'Lu', An Experimental Study on the Effect of Konis Angle Variations on the Pendulum Motion Pattern and Resurrection Voltage in a Konis Pendulum System Wave Power Generation (PLTGL-SB) Power Simulator. Surabaya: Sepuluh November Institute of Technology, 2011. 